\title{
THE IMPACT OF DIGITALISATION ON HUMAN RESOURCES DEVELOPMENT
}

\author{
Ardelin LUMI (iD \\ University of Prishtina “Hasan Prishtina”, Faculty of Economic, ardlin.lumi@ gmail.com
}

\section{Article history:}

Submission 08 August 2020

Revision 12 September 2020

Revision 22 September 2020

Accepted 05 November 2020

Available online 31 December 2020

\section{Keywords:}

$H R M$,

Digitalisation,

Artificial Intelligence,

Process,

Technology.

\begin{abstract}
A b s t r a c t
The paper is a summary of the studies conducted by several authors on the impact of digitalisation on human resource management. In the paper the filtering is done by classifying the authors according to the data and results. The first division presents a general summary of the positive and negative aspects of Digitalisation in HRM processes. The second section talks about the impact of digitalisation on the recruitment process, its impact on the recruitment process, the changes which happened in the improvement aspects. The latest part emphasizes the impact of digitalisation on the training and development process, on the importance of digitalisation in training in this case in the hotels' sector. The literature used in the paper is mainly taken from prestigious journals to increase the quality of the paper, as well as geographical filtering of the works which has been done in this relation, taking works by authors from different countries. Digitalisation is one of the essential processes of technological change, changes that affected every HRM process. The drastic changes made in human resources have created and accelerated many other changes in HR processes. Most authors point out that digitalisation and technological developments have created an ever-changing era, some of them emphasize the importance of digitalisation at work, and some others think that the HRM course has changed completely. Russian authors discuss the impact of the Digitalisation process on employees by discussing the aspect of negative sides. Nevertheless, all the authors agree that digitalisation and technological change are inevitable and that investing in this aspect is indisputable. As the world rotates, everything is in motion.
\end{abstract}

\section{Introduction}

The world is continually changing, every moment circumstances change (situation, environment, technology, etc.), any change affects the organization, whether in decision making or any area of the organization's management. We are witnessing enormous changes brought by technology hence creating a completely different flow; it changed the approach and business prospects. In fact, every day we have a fusion of technology within every sphere of life, in every day more and more we adapt our daily actions according to these changes, and as a result, technology facilitates our life in general. This made it one of the most current and studied topics continuously. Any organization tends to have in its ranks people with the right skills and abilities to perform the certain tasks, but this is only one of many requirements of the HR department.
An obvious problem in all organizations today is the human resources management, the maintenance of the employees, fluctuation stoppage, evaluation etc. Today organizations use advanced methods and systems for human resource management. The impact of technology especially the information technology is very emphasized in the economy knowledge where information is the primary input. Human resource management has changed over the years from the traditional style of HR creating a human resources strategy, to the impact of technology on improving the quality of human resource performance.

2. Literature Review About The Impact of Digitalisation in Human Resources Development 
Regarding the impact of Digitalisation on human resource development have been conducted several essential research papers by various authors. Researchers have generally tried to identify the importance of Digitalisation in increasing employee performance as well as the growth of effectiveness of the work they perform. Alena Federova, Anastasia Zarubina, Yulia Pikulina, Aleskey Moscovskikh, Tatiana Balandina, Tatiana Gafurova in their research Digitalisation of the Human Resource Management highlight the fact that: Digitalisation, automation, and robotization have a significant impact on labour market transformation. New technologies are changing the usual functionality of workers in various professional fields. Digital tools are introduced in business processes, including human resources management processes (Federova, Alena Zarubina, Anastasia Pikulina, Yulia Moscovskikh, Aleskey Balandina, Tatiana Gafurova, Tatiana, 2019).

Jane Indira JA emphasizes that: Digitalisation is a tool that speeds up the communication process by reducing cost, and helping organizations be more productive and work more efficiently and be more effective. (Indira, Jane, 2020). Jeroen Meijerinka, Mark Boonsb, Anne Keeganc and Janet Marlerd found that: HRM is affected indirectly from how Digitalisation developments may affect the future of work. Digital technologies will change the organization and nature of work (Meijerinka, Jeroen Boonsb, Mark Keeganc, Anne Marlerd, Janet, 2018). Camila Bengston, Moa Bloom found that: Perceptions of changing customer preferences are only a small fraction when viewed through a wider lens, as digitization changes general human behaviour; it gives the sense that everyone is affected (Bengsston, Camila Bloom, Moa, 2017). Deotima Saha and Deepika Pandita in their research found that: Employees of the Industrial Revolution known to be manual workers and those of the Information Age as employees of knowledge, employees in today's Technological era are a new type of generation known as Native Digital (Saha, Dontima Deepika, Pandita, 2017).
Pratyush Tripathi found that: E-HRM allows all performance appraisals to be done online, on the corporate web interface. This means that the manager and employee can submit performance data directly to the Human Resources department in electronic form. This practice, although is criticized for lack of written evidence, reduces paperwork. Receipts are used for both directors and supervisors, and they can significantly reduce time and cost for the HRM department (Tripathi, Pratyush, 2013).

Digitalisation is a natural development at work. The digital office covers all the technologies that people use to work - both currently in operations. (Aradhna, Yadav Jacob, Alexander Veenam Shenoy, 2007).

Digitalisation in human resource management helps enterprises to modernize human resource functions and provides them with a competitive advantage (Anastasiia Mazurchenko, Kateřina Maršíková, 2019).

Alena Federova and Olga Koropets in their publication Digitalisation of human resource management practices and its impact on employee wellbeing among others found: According to that, the following data are taken. The majority of respondents $(86 \%)$ fear work stoppages associated with sudden power outages and "freezing" of computer equipment; $52.6 \%$ of respondents fear that the elderly will lose their jobs due to difficulties in mastering new technologies; $17.5 \%$ of respondent's point to the high cost of new technologies and low-quality software they use. The risk of unemployment due to robotization worries $21 \%$ of respondents; $14 \%$ indicated potential risks of damaging database loss. There have also been individual concerns about the degradation of thinking ("a computer will think of us and our thinking will degrade"), a negative impact on the ability to express our thoughts grammatically and synthetically correctly, and the fear of the fall of "humanity" in the social sphere. (Federova, ALENA Koropets, OLGA, 2019).

Table 1. An example of A narrative analysis of the thematic core "Potential concerns about the introduction of information and communication technologies in organization of work).

\begin{tabular}{|c|c|c|}
\hline Concerns & Keywords & Quotes \\
\hline $\begin{array}{l}\text { Technology } \\
\text { malfunction }\end{array}$ & $\begin{array}{l}\text { electrical } \\
\text { energy, } \\
\text { glitches } \\
\text { program, } \\
\text { technical errors, } \\
\text { freezing, e } \\
\text { impossible for } \\
\text { him }\end{array}$ & $\begin{array}{l}\text { "I work as a teacher. Devices can fail at any time, computer } \\
\text { can be turned off, an energy failure can occur, and animation } \\
\text { will not work due to change in-office program. } \\
\text { Therefore, it is not a fact that the classic board is not useful. "Only you have to turn off the } \\
\text { electricity, and all the work in our office is on paralyzed." }\end{array}$ \\
\hline
\end{tabular}




\begin{tabular}{|c|c|c|}
\hline & worked & \\
\hline $\begin{array}{c}\text { Unappropriate } \\
\text { quality of } \\
\text { equipment }\end{array}$ & $\begin{array}{c}\text { cost, price, } \\
\text { quality of } \\
\text { small software, } \\
\text { quality } \\
\text { equipment }\end{array}$ & $\begin{array}{l}\text { "The quality of the equipment is not always adequate; our organization } \\
\text { cannot afford expensive equipment and high quality software. " } \\
\text { "Unfortunately, for the full Digitalisation of work, there are no programs } \\
\text { qualitative enough. The ones that work available slowly and freeze." }\end{array}$ \\
\hline $\begin{array}{l}\text { difficulties } \\
\text { in possession } \\
\text { technology } \\
\text { faced } \\
\text { the elderly }\end{array}$ & $\begin{array}{l}\text { retirement age } \\
\text { skills difficulties } \\
\text { for } \\
\text { mastery, the } \\
\text { elderly, } \\
\text { adaptation of } \\
\text { pensioners, } \\
\text { adult generation }\end{array}$ & $\begin{array}{l}\text { "The elderly will find it harder and harder to find one } \\
\text { job because they have little in terms of digital skills. " } \\
\text { "The adult generation does not adhere to technologies (given the growth of retirement age, it } \\
\text { is difficult to adapt)" }\end{array}$ \\
\hline $\begin{array}{l}\text { Unemployment } \\
\text { for } \\
\text { due to extinction } \\
\text { of works }\end{array}$ & $\begin{array}{c}\text { robotization of } \\
\text { job losses, } \\
\text { eradication of } \\
\text { unemployment } \\
\text { professions }\end{array}$ & $\begin{array}{l}\text { "Robotics threatens the extinction of several recruitment functions." "I am afraid that a } \\
\text { number of professions will disappear because of robotics and Digitalisation, and I will have } \\
\text { nowhere to work. " }\end{array}$ \\
\hline $\begin{array}{l}\text { Loss risk of } \\
\text { data }\end{array}$ & $\begin{array}{l}\text { hackers, data } \\
\text { loss, } \\
\text { data theft of } \\
\text { personal } \\
\text { information }\end{array}$ & $\begin{array}{l}\text { "In our work, there is always the risk of data retaliation, } \\
\text { theft of copyright technologies. "Once, an employee } \\
\text { in our office, when fired, copied the client base for } \\
\text { his personal use and it was not possible to prove anything. " }\end{array}$ \\
\hline
\end{tabular}

Source: Federova, ALENA Koropets,OLGA, Digitalisation of human resource management practices and its impact on employees' well-being, 2019.

According to Deloitte of this year study, only $38 \%$ of companies are even thinking about digital HR, and only $9 \%$ are fully ready. Nearly three-quarters of companies, or $72 \%$, believe this is a significant priority, and $32 \%$ identify it as very important so that it will be a large area of opportunity for HR in 2016. See the figure 1 for our survey respondents' estimates. The importance of digital HR in global regions and selected numbers. 
Figure 1. Digita HR: Percentage of respodents rating this trend "important" or "very important".

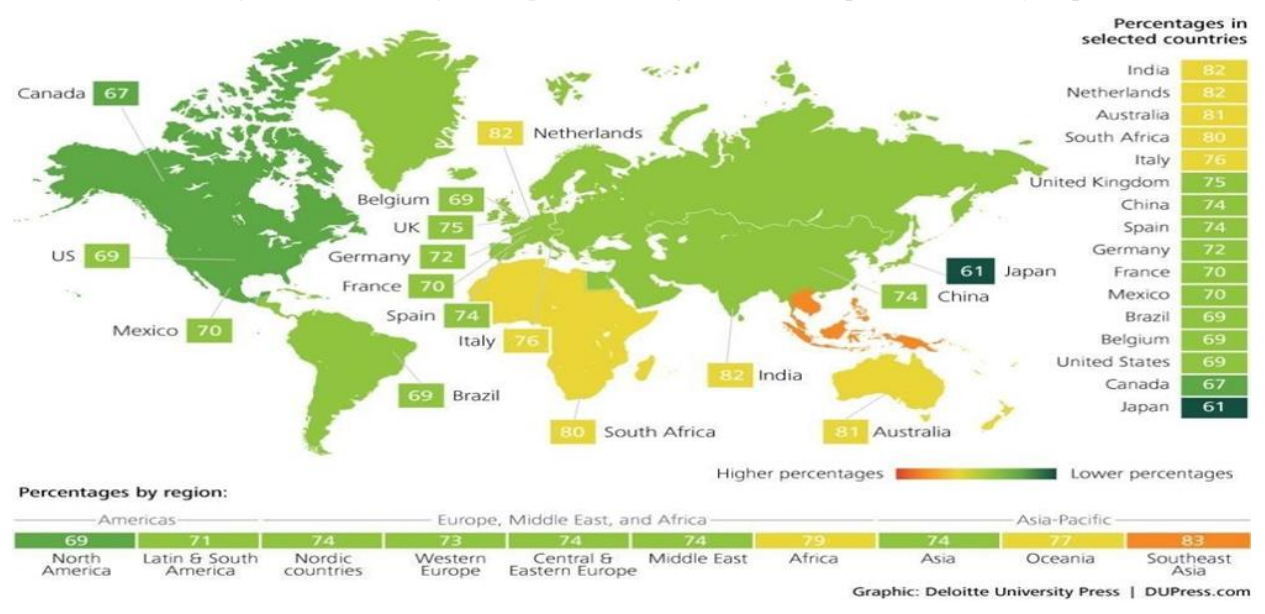

Source: Digital Transformation and its Impact on Organizations' Human Resource Management

Eshan and Binoy (2018) in their work emphasize that Digitalisation has a great impact on the recruitment process and on the training-development of the workforce:

1.1 - Digitalisation in recruitment: Recruitment and selection are the first and most important functions of HRM. The HRM process starts with the recruitment, followed by the completion of the selection of the candidate. Now the global human resource employment revolution has become easy and cost-effective due to the online social network. Electronic recruitment is designed to make the recruitment process more efficient and effective. The candidate can complete their necessary information (Resume) name, email, experience, qualifications and skills after completing all the details that the candidate can upload the resume. The company recruitment team will shortlist, and they will inform the candidate again. Even with the help of digitalisation, many companies use social media platforms like Facebook, LinkedIn, Skype (video conferencing) etc.

1.2 - Digitalisation in Training and development: is one of the constituent parts of the star hotel industry. Proper training and development provided to employees will lead to the success in the goals and objectives of the organisation. In the past, hotel training and development took place through demos, lectures, book references, which took time usually time and effort for management to engage staff in training and development.

However, due to digitalisation in training and development, the human resources department has moved forward. Modern technology which has been used like displaying work-related videos, online courses, computerised learning methods, reading through soft copies has revolutionised teaching techniques. Once the employee joins the hotel, management creates employee documentation and creates a personalised account for that employee. All SOPs (Standard Operating Procedures) of hotel operations are stored on the computer, and any employee who feels difficult in performing the work can refer to the SOP fed into the system and move forward with his tasks. (Mr.Eshan, Dr.Binoy, 2018)

Author Pranjali Gagali in another research, pays attention to the impact of digitalisation on social networks as well as its significant impact, which has managed to bring a new reform in business. In recent years, digitalisation has deepened confidence in data analytics, social networking, and mobile technologies, and has dramatically reformed the role of communication in business. To take advantage of technological advances towards stakeholder engagement as well as adaptation to digital transformation, some organisations have taken substantial steps to develop a strategic framework for organisational priorities. Business executives have played a vital role in including paradigms by fostering newer perspectives on human communication, reducing functional hierarchies, and supporting the engagement of internal and external stakeholders. It is clear that while digitalisation has brought many challenges, it has also allowed organisations to reformulate their public image, build meaningful value-based dialogue on public platforms, and strengthen their objectives through a well-designed function, of human resource management (Pranjali Galgali, 2018).

Author Volker Stein on digitisation states that; taking a closer look at digitalisation, it is defined as the digital representation of signals, information and objects in binary code, enabling computer processing as underlying technology and propulsion of convergence between technological applications of different application fields. Digitalisation has penetrated all spheres of today's business world or contemporary automated manufacturing. In terms of flow effects, it also offers benefits to traditional spheres by making more effective and efficient resources available. Industry 4.0 (cyber system), the Internet of 
Things or ubiquitous computing make it a digital megatrend. Nevertheless, digitalisation also has a dark side, as it created new inequalities between individuals, social groups, organisations and nations over digitalisation infrastructure, investment in technology equipment and digitalisation capabilities - the socalled "digital divide" (Volker Stein, 2015).

Meanwhile, according to the E-commerce Europe Report for Eastern Europe, the lowest level of e-commerce business use among European countries is observed in Eastern European countries. In 2012, e-commerce turnover in the emerging economies of Russia, Bulgaria, Romania and other countries reached 13.4 billion Euros, an increase of $32.6 \%$ compared to 2011. The leading country also in terms of population the most promising in the e-commerce market in this part of Europe is Russia, with a growth of $33 \%$. In 2013, online sales of goods and services across Eastern Europe were estimated to have reached 19.3 billion euros, which is significantly lower than in Western European countries but with an increase from a year ago. (SHERIFI, Idaver, 2015)

\section{Study Purpose and Methodology}

\subsection{Study purpose}

The purpose of this research is to analyse the importance of technology on human resource development, the strengths and weaknesses that arise-seeing that we are living in an age of technology where everything is changing. The impact of technology is irreplaceable always a need for analysis of the impact of technology management. Ensuring competitive advantage in the market is one of the main challenges of organisations, and this priority is made by human resources, their selection, recruitment, management, evaluation is yet another challenge. A connection between these factors is made possible by technology. In the knowledge market, information is the primary source, and this source is easily accessible through the use of technology. For these reasons, analyses on the impact of technology on human resource management are numerous, because technology provides facilities in human resource management.

\subsection{Study Methodology}

On the methodological aspect of the paper, this paper was prepared using analytical methods with secondary data obtained from previous papers related to the digitalisation process in human resource management. The paper is constructed from secondary, descriptive data and presents a general summary of some papers; the papers are filtered classifying them by similarity.

\section{Results of Secondary Data}

Human life and technology are closely linked; technology has been and is continuously making human life more comfortable. There is a strong correlation between them that has revolutionized the economy, leading every process towards Digitalisation, creation, transfer, storage, dissemination of information, transcending time limits and reducing costs. Providing human resources for companies changed its access, expanded the market, eased access to data, increased performance monitoring and many other things provide Digitalisation "new era" and these changes began to become competitive advantages for businesses, providing advantages competitive through human resources.

Regarding the impact of Digitalisation on the development of HR, many researchers have been applying it which emphasizes the importance of Digitalisation in some processes in HR, emphasizing the positive and negative sides of Digitalisation. A. Federova, A. Zarubina, Y. Pikulina, A. Moscovskikh, T. Balandina, T. Gafurova in their research Digitalisation of the Human Resource Management pointed out that: Digitalisation, automation, and robotization have a significant impact on labour market transformation while J. Indira emphasizes that: Digitalisation is a tool that speeds up the communication process while reducing costs and helps organizations to be more productive and work more effectively and efficiently. $\mathrm{J}$. Meijerinka, M. Boonsb, A. Keeganc and J. Marlerd point out that those digital technologies will change the organization and nature of work. Pratyush Tripathi found that: E-HRM allows all performance appraisals to be done online, on the corporate web interface. Digitalisation in human resource management helps enterprises to modernize human resource functions and provides them with a competitive advantage, emphasizes A. Mazurchenko and K. Marsikova. All the authors mentioned above have emphasized the importance of Digitalisation (technology) in the management process of the HR management process in the transformation of the labour market, process acceleration, communication, efficiency, effectiveness, changing the nature of work, evaluation of performance. All of these are practices already proven by many companies, known as the benefits of Digitalisation. All life today is digitalized, but there are groups of people who think differently about Digitalisation and its impact. In the research of Alena Federova and Olga Koropets Digitalisation of human resource management practices and its impact on employee wellbeing among others found: According to the thematic essence "Possible concerns regarding the introduction of information and communication / digital technology in the organization of work", the following data were obtained. The majority of respondents $(86 \%)$ fear work stoppages associated with sudden power outages and "freezing" of computer equipment; $52.6 \%$ of respondents fear that the elderly will lose their jobs due to difficulties in mastering new technologies; 
$17.5 \%$ of respondents point to the high cost of new technologies and the low-quality software they use. Unemployment risk due to robotization worries $21 \%$ of respondents; $14 \%$ indicated potential risks of damaging database loss. These data from the research of Alena Federova and Koropet conducted in Russia show a disturbing fact that not all societies are ready for the Digitalisation process. Digitalisation also has a dark side, as it created new inequalities between individuals, social groups, organizations and nations over Digitalisation infrastructure, investments in technology equipment and Digitalisation capabilities - the socalled "digital divide" says Volker Stein.

Digitalisation in Recruitment: Recruitment is one of the first and most important processes of HRM. The impact of Digitalisation (technology) is more pronounced in this process where the recruitment process has completely changed. Mr Eshan and Dr Binoy in their paper emphasize that the candidate can complete their necessary information (Resume) name, email, experience, qualifications and skills after completing all the details that the candidate can upload there resume and that most of the companies today use social networks like Facebook, LinkedIn, Skype (video conferencing) etc. for recruitment. Today there are different platforms in terms of recruitment platforms which thanks to rapid technological developments are continually changing, and it must be said that Digitalisation has increased the effectiveness of the recruitment process.

Digitalisation in Training and development: But due to Digitalisation in training and development, the human resources department has moved forward. Modern technology which has been used as the display of work-related videos, online courses, computerized learning methods, reading through soft copies has revolutionized teaching techniques, says Mr Eshan and Dr Binoy in their research on the impact of Digitalisation of training and development in the hotel sector by making comparisons with the previous time, where training and development in hotels took place through demos, lectures, book references. While now managers have created accounts on the computer where they store training and where they can serve as a reference for specific problems.

\section{Critical Evaluation}

The future is often a myth, unpredictable, but we have to be prepared for everything. Those who think that they can escape the "new age" are wrong. Digitalisation should be understood as a technological process that has already taken place, while the technology itself represents the new human era, which for many societies sees it from a negative perspective because they are not ready for change. It must be understood that adaptation is the primary weapon against change and that some things are inevitable. Human nature has always been divided into two camps in terms of technology, the "optimists" who have embraced this change and the "pessimists" who continue to oppose it, but everything has to do with the point of view of how we see things. Technology has its impact in every field, be it social, economic or social life itself today is technology, we live in a time when everything is related to technology.

Nevertheless, nothing can replace the human mind; always, the creator is superior. The world's economy has embraced the spirit of change, where everything is adapted to it, and where change has affected the field of Human Resources in almost all its processes such as recruitment, selection, performance, training and development, monitoring and processes others. Digitalisation has dramatically improved human resource management by making it more efficient and effective by facilitating any process. Technology is changing so fast that what gives you an advantage today after a while may be a weakness for you. We can say that technology has broken the essence of time and space, where everything happens in relation to time and space, where the world is more connected than ever. Digitalisation has almost completely changed the management of human resources where all processes have been improved were providing the right people for the job is no longer a problem. However, many organisations continue to avoid the digitalisation process, and this penalises them in the market. Businesses need to invest more in this aspect. Most authors emphasise on digitalisation and technology in general, in internal focus, not once should we use people as tools, the primary basis of an organisation is the people, and the tools are for you to use not people. Digitisation is not created to underestimate human being, but to support him/her, to facilitate his/her work. In the business world, everything is a chain link where all processes are interconnected, where the market is the arena (place) of war, where the consumer is the central pillar (Target, Trophy), where the company is the tool and where the people of the company are the engine its like a race track.

\section{Conclusions and Recommendations}

\subsection{Conclusions}

The digital transformation of human resource management is completely changing the course of the process, radical changes in technology, automation and Digitalisation have changed the traditional form of work, the introduction of artificial intelligence in HRM processes has facilitated problem-solving and automation of some processes. The World Economic Forum study highlighted the competencies that by 2020 will become the highest priority for employers, namely: the ability to solve complex tasks, critical thinking, creativity, ability to manage people, ability to collaborate with others, emotional intelligence, prudence and decision making, service orientation, negotiation 
skills, cognitive flexibility (Gray, 2016). The correlation that exists between technological processes (Digitalisation, automation ..) and HR processes (recruitment, selection, performance ...) is extremely pronounced. Radical, rapid change is rapidly increasing the need for an advanced workforce in both its use and adaptation, making this link between Digitalisation and human resources a productive power that resists stiff competition and frequent changes. HRM processes have undergone significant changes which continue today, the recruitment and selection process has changed, with digital platforms, international connections, globalization, social networks and many other aspects that have influenced, training and digital forms of communication have shown its importance even in crisis and pandemic situations such as the current COVID pandemic situation19. Nevertheless, we must not stop discussing the achievements of Digitalization, they must be practised, and every innovation every method, successful strategy must be implemented, organizations must allocate funds in terms of technological developments.

\subsection{Recommendations}

Although much research has been done on the impact of digitalisation and other technological processes on human resource management, the main power of technological developments remains in large organizations, the multinational ones which dominate the global market, due to the financial strength many enterprises cannot invest in these changes and stay out of the market, the transition countries also have significant problems which face difficulties in technological adoptions, therefore the state should support enterprises in this regard. Organizers need to share tools and people in the digitization of processes. In the market time is everything, keeping pace with constant change for many companies is overwhelming and fatal in some cases, but today different forms of business are being implemented and markets are expanding, many companies are merging among themselves to face competition. At this rate of change the expectations are that the world concretely economy will change completely and survival will be difficult. The most erroneous decision that an enterprise can make is to bypass change, today we have numerous examples of companies that have failed in this regard (e.g. NOKIA). Digitalisation as a process is entering a completely different phase and very soon is expected to belong to the past, today in the knowledge economy where the cyber system is practiced, is the latest word of technology. But in a changing world where technology changes, so do people, changing requirements, consumer desires, with an ever-increasing demand there is hope for everything and innovations are always welcome and make us more visionary.

\section{References}

1. Fedorova, A., Zarubina, A., Pikulina, Y., Moskovskikh, A., Balandina, T., \& Gafurova, T. (2019). Digitalization Of The Human Resource Management: Russian Companies Case. International Conference on Education, Social Sciences and Humanities, 1227-1230.

2. Anastasiia Mazurchenko, K. M. (2019). DigitallyPowered Human Resource Management:Skills and Roles in the Digit. Mukt Shabd Journal, 72-87.

3. Aradhna, Y. J. (2007). The existentialism of Digitalisation era in Human Resources. Mukt Shabd Journal, 30-83.

4. Bengsston, C. B. (2017). Human Resource Management on digital era. LUP Student Papers, 030 .

5. Federova, A. Z. (2019, May). Digitalization of the Human Resource Management. Russian Companies Case.

6. (2015). Impact of Information SystemsiIn Entrepreneurship). Ditët e Studimeve Shqiptare II.

7. Indira, J. (2020). Digitalisation of Human Resource Management: A Changing Role in Digital Transformation. UGC Care Listed Journal, 156-157.

8. Meijerinka, J. B. (2018). Digitization and the transform of the Human Resources Management,. The International of Human Resource, 3-5.

9. MR. Eshan, D. (2018). The Role of Digitalization in Human Resource Management in Star Category hotels, A review. Journal of Emerging Technologies and Innovative Research (JETIR), 206.

10. P Galgali. (2017). Digital Transformation and its Impact on Organizations' Human Resource Management. IOR and Stakeholder Managment, MCM, School of Communication and Information, Rutgers University.

11. Saha, D. D. (2017). Digitalizing Human Resources Through Gamification for Employee Engagemet. Asia Pacific Journal. - 978-93-85537-03-5. 4'th IHRC. Avaible at: https://www.researchgate.net/profile/Deepika_Pandit a2/publication/323748863_DIGITALIZING_HUMA N RESOURCES THROUGH GAMIFICATION F OR EMPLOYEE ENGAGEMENT/links/5aa8e4eb0 f7e9b0ea3083dfa/DIGITALIZING-HUMANRESOURCES-THROUGH-GAMIFICATION-FOREMPLOYEE-ENGAGEMENT.pdf

12. Stein Volker. ((2015). Human Resources Development in times of Digitalisation. Arbeitspapiere. 
13. Tripathy, P. (2013). Digitalisation in Performance

Management. p. 0-72. Avaible at: www.ircjournals.com 